\title{
STUDY ON SITE CONDITIONS BASED ON TOPOGRAPHIC SLOPE
}

\author{
Wu Xiaoyong, Wang Xiaoqing*, Yuan Xiaoxiang, Chen Meng, Dou Aixia \\ Institute of Earthquake Forecasting, China Earthquake Administration, Beijing 100036, China - (zeenwxy, \\ wangxiaoq517)@163.com
}

Commission III, ICWG III/IVa

KEY WORDS: DEM, Topographic Slope, Vs30, Site Conditions

\begin{abstract}
:
The travel-time averaged shear-wave velocity to a depth of 30m (Vs30) below the Earth's surface is widely used to classify sites in many building codes. Vs30 is also used to estimate site classification in recent ground-motion prediction equations (GMPEs), and the distribution of Vs30 has been mapped in a region or country. An alternative method has recently been proposed for evaluating global seismic site conditions or Vs30, from the SRTM (Shuttle Radar Topography Mission) DEMs (digital elevation models). The basic premise of the method is that the topographic slope can be used as a reliable proxy for Vs30 in the absence of geologically and geotechnically based site-condition maps through correlations between Vs30 measurements and topographic gradient. Here, we use different resolutions ( 3 arcsec, 30 arcsec) DEM data to get Vs30 data separately, analyze and compare the difference of Vs30 data and site conditions obtained from different resolution DEM data. Shandong Province in eastern China and Sichuan Province in Western China are studied respectively. It is found that the higher resolution data is better at defining spatial topographic features than the 30c data, but less improvement in its correlation with Vs30.
\end{abstract}

\section{INTRODUCTION}

Vs30, the time-averaged seismic shear-wave velocity (Vs) to a depth of 30 meters below the Earth's surface, is proved to be a key index adopted by the earthquake engineering community to account for seismic site conditions (Borcherdt, 1992; Boore, 2006). Although variations in medium properties at depths of tens to hundreds of meters below the Earth's surface are known to significantly influence ground motions, deeper variations are also important (Boore, 2004). Nevertheless, several studies (Borcherdt, 1994; Wills and Silva, 1998) have found good correlation between observed site amplification and Vs30. As a result, the Vs30 parameter has widely adopted as the key parameter for site characterization.

Vs30 is typically based on geophysical measurements of Vs derived from invasive and noninvasive techniques at sites of interest. Owing to cost considerations, as well as logistical and environmental concerns, Vs30 data are sparse or not readily available for most areas. Besides, some drilled boreholes are shallower than $30 \mathrm{~m}$ for a variety of reasons. For Vs30 profiles with depth less than $30 \mathrm{~m}$, Boore (2004) provided several models to estimate Vs30:

$$
\begin{aligned}
& \overline{\mathrm{v}_{\mathrm{S}}}(\mathrm{d})=\frac{\mathrm{d}}{\mathrm{tt}(\mathrm{d})} \\
& \mathrm{tt}(\mathrm{d})=\int_{0}^{d} \frac{d z}{v_{S}(z)}
\end{aligned}
$$

$$
\begin{array}{ll}
\text { where } & \begin{array}{l}
\mathrm{d}=\text { depth } \\
\mathrm{tt}(\mathrm{d})=\text { travel-time } \\
\end{array} \\
\text { of } \mathrm{z} & \mathrm{Vs}(\mathrm{z})=\text { Shear wave velocity of soil layer with depth } \\
& \mathrm{Vs}(\mathrm{d})=\text { Mean shear wave velocity in the range of } \mathrm{d}
\end{array}
$$
from surface to underground depth

While Vs30 maps have traditionally been derived directly from geological maps, several studies (Wald and Allen, 2007; Yong et al., 2008a; 2008b) have exploited newly available remote sensing data to develop site classification maps. As one of the earliest studies utilizing satellite imagery to account for site conditions, Romero and Rix (2001) used Landsat 7 Enhanced Thematic Mapper Plus (ETM+) data to interpret the character of surficial sediments for estimating the potential of ground shaking in the Mississippi Embayment. Using SRTM DEMs, Wald and Allen (2007) presented global Vs30 maps based only on topographic slope.

All approaches for deriving Vs30 have uncertainties. Moreover, Vs30 does not capture all the underlying physics that control site amplification; thus, use of this parameter to describe site response has been the subject of debate (Lee, 2010; Wills, 2006; Zhao, 2013).

Here, we use different resolutions (3 $\operatorname{arcsec}, 30 \mathrm{arcsec}$ ) SRTM DEM data to get Vs30 data separately, analyze and compare the difference of Vs30 data and site conditions obtained from different resolution DEM data.

\section{EXPERIMENTS AND ANALYSIS}

The SRTM data were gathered in February 2000 by the Shuttle Radar Topography Mission using an Interferometric Synthetic Aperture Radar (InSAR) instrument (Farr and Kobrick, 2000). The 11 day mission mapped approximately $80 \%$ of the global landmass using $C$-band $(\lambda=5.6 \mathrm{~cm})$ and X-band $(\lambda=3.0 \mathrm{~cm})$ wavelengths.

We use DEM data of 30 arcsec and 3 arcsec to characterize the relationship in terms of discrete steps in shear velocity values tied to NEHRP (National Earthquake Hazards Reduction Program) Vs30 boundaries. Then, according to the NEHRP specification (Table 1), the site classification in the study area will be obtained.

\begin{tabular}{|c|l|l|}
\hline Site Class & Soil Profile Name & Vs30 (m/s) \\
\hline A & Hard rock & $>1500$ \\
\hline
\end{tabular}




\begin{tabular}{|l|l|l|}
\hline B & Rock & $760-1500$ \\
\hline C & Very dense soil and soft rock & $360-760$ \\
\hline D & Stiff soil & $180-360$ \\
\hline E & Soft soil & $<180$ \\
\hline
\end{tabular}

Table1. NEHRP site classes (Wald et al., 2007)

Slope ranges for each bin were based on initial regression analysis, but final assignment of starting and ending slope bins required subjective modification where there were fewer data to constrain the regressions. Topographic slope at any site that falls within these windows is assigned a Vs30 by interpolating over the subdivided NEHRP boundaries based on that slope value (Table 2).

\begin{tabular}{|c|c|c|c|}
\hline Class & $\begin{array}{c}\text { Vs30-range } \\
(\mathrm{m} / \mathrm{s})\end{array}$ & $\begin{array}{c}\text { Slope-range }(\mathrm{m} / \mathrm{m}) \\
\text { (active tectonic) }\end{array}$ & $\begin{array}{c}\text { Slope range }(\mathrm{m} / \mathrm{m}) \\
\text { (stable continent) }\end{array}$ \\
\hline E & $<180$ & $<1.0 \mathrm{E}-4$ & $<2.0 \mathrm{E}-5$ \\
\hline \multirow{3}{*}{$\mathrm{D}$} & $180-240$ & $1.0 \mathrm{E}-4-2.2 \mathrm{E}-3$ & $2.0 \mathrm{E}-5-2.0 \mathrm{E}-3$ \\
\cline { 2 - 4 } & $240-300$ & $2.2 \mathrm{E}-3-6.3 \mathrm{E}-3$ & $2.0 \mathrm{E}-3-4.0 \mathrm{E}-3$ \\
\cline { 2 - 4 } & $300-360$ & $6.3 \mathrm{E}-3-0.018$ & $4.0 \mathrm{E}-3-7.2 \mathrm{E}-3$ \\
\hline \multirow{3}{*}{$\mathrm{C}$} & $360-490$ & $0.018-0.050$ & $7.2 \mathrm{E}-3-0.013$ \\
\cline { 2 - 4 } & $490-620$ & $0.050-0.10$ & $0.013-0.018$ \\
\cline { 2 - 4 } & $620-760$ & $0.10-0.138$ & $0.018-0.025$ \\
\hline B & $>760$ & $>0.138$ & $>0.025$ \\
\hline
\end{tabular}

Table2. Summary of slope ranges for subdivided NEHRP Vs30 categories (Wald et al., 2007).

Wald et al. (2007) gave two sets of empirical relationships between slope and Vs30: (1) Tectonically active regions with significant topography; (2) Stable continental regions with relatively gentle terrain changes (Table 2). After judging the tectonic activity of geology, Vs30 can be calculated by using Table 1. The concrete steps are as follows:

(a) The area is meshed with a certain size and the calculation of the maximum slope value in the terrain data is done by the "grdgradient" command of GMT (general mapping tool) (Wessel et al., 1991) or the "slope" tool of ArcGIS.

(b) According to the study of Wald and others (Allen et al., 2009; Wald et al., 2007), the geological tectonic activity of the region is judged by the average slope, that is, it belongs to the active region or the stable area.

(c) We get the slope size of every grid point location based on DEM data. According to Table 1, we can get the range of site shear wave velocity Vs30 at the location of grid point.

(d) According to the range, we can get the Vs30 value at this location by interpolation or median value, and we can also determine the site category of the grid points (Figure 1).

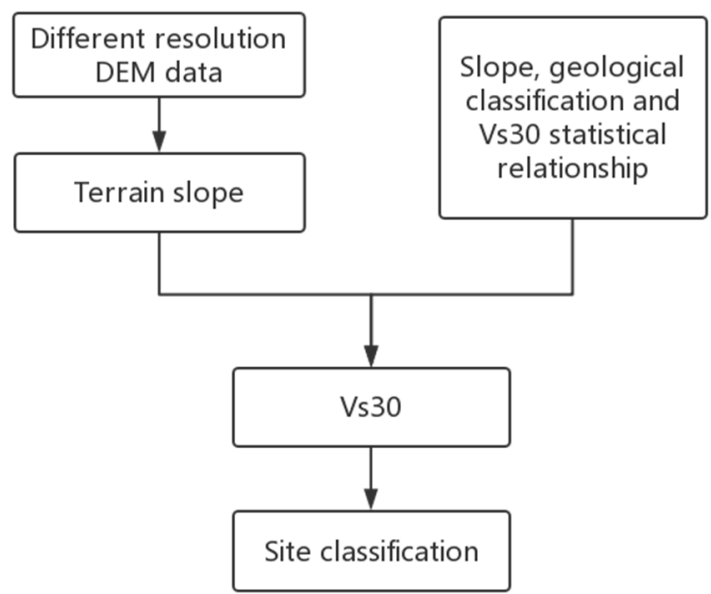

Figure 1. Flow chart of site classification calculation

In this way, we can get the data value of the Vs30 grid in the study area, and then use the ArcGIS drawing tool to get the Vs30 distribution map of the research area.

The topography of China, shown in Figure 2 by using SRTM 30s DEM data, is a ladder-like distribution low with many plains in the east and high with vast mountains in the west. Shandong Province, whose economy is developed and population is large, is located in the eastern coastal area, and it is run through the Tanlu fault zone. Once the natural disasters occur, such as earthquake, the consequences are unimaginable. Sichuan province is located in the North South seismic belt area, which is an earthquake prone area. Thousands of people suffered from Wenchuan, Lushan and other earthquakes. Therefore, we choose two research regions, one is Shandong Province in the eastern plain areas, the other is Sichuan Province in the western mountainous areas. Of course, the eastern part of Sichuan is flat and partially plain, and parts of Shandong are also mountainous.

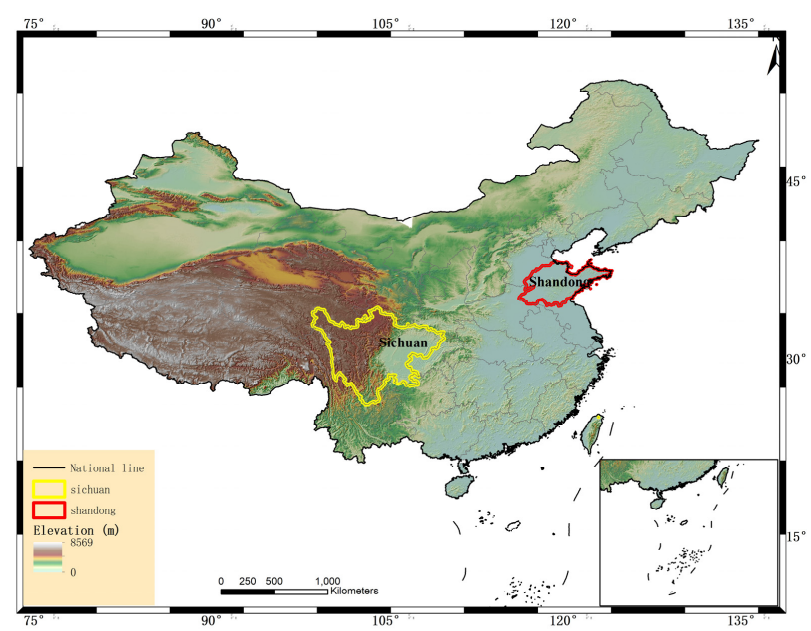

Figure 2. Chinese topographic map (data source: SRTM DEM $30 \mathrm{~s})$

Figure 3 and Figure 4 show the terrain of the study area. It is found that the 3 arcsec terrain data can better characterize the surface morphology than the 30 arcsec topography data. 


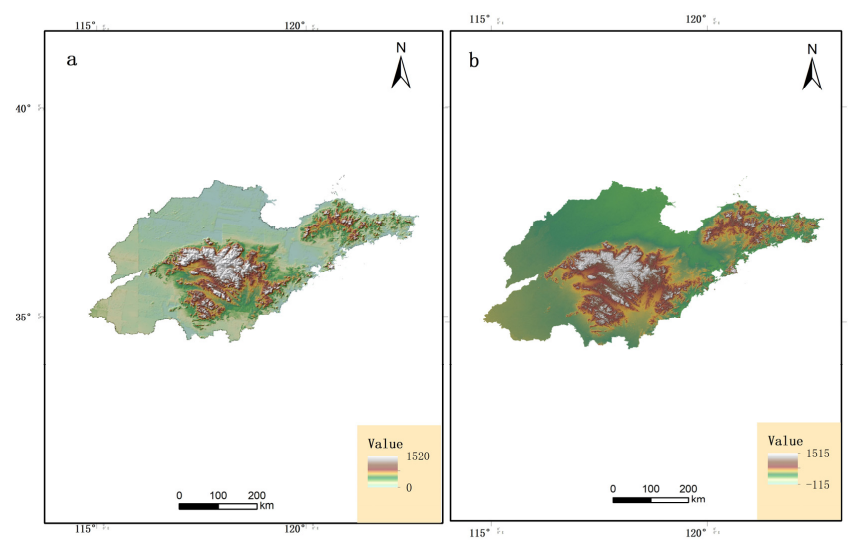

Figure 3. (a) and (b) The topographic map of Shandong province obtained by using 30 arcsec and 3 arcsec DEM data respectively.

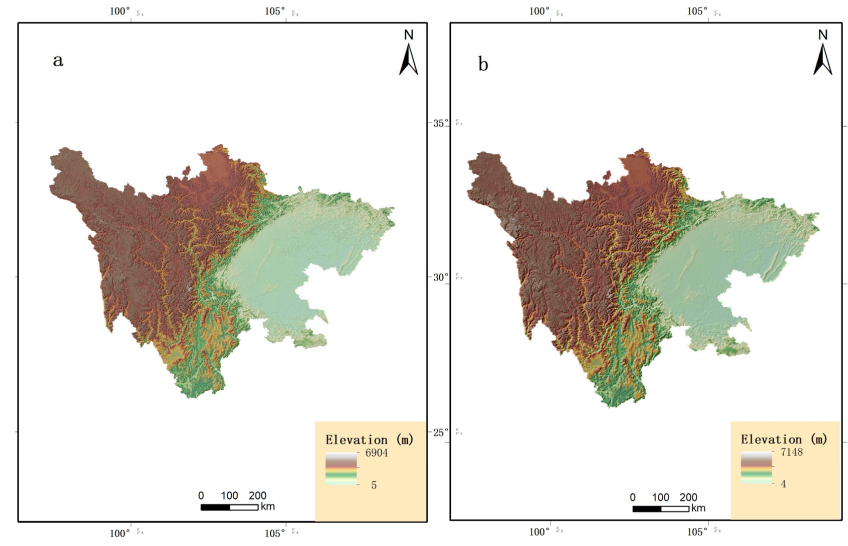

Figure 4. (a) and (b) The topographic map of Sichuan Province obtained by using $30 \operatorname{arcsec}$ and $3 \operatorname{arcsec}$ DEM data respectively.

The slope of the study area is calculated by GMT. The Shandong area is mostly plain, and the average slope is less than 0.05 , which is the relatively structural stability area. Sichuan area is mostly mountainous, with an average slope of about 0.05 , which belongs to the relatively active tectonic area. According to the statistical relationship of Wald (Table 2), we can get the Vs30 distribution in the study areas (Figure 5 and Figure 6). The higher resolution data resolved a consistent higher slope, while the lower sampling rate of the 30 arcsec dataset itself smoothed the maximum slope value on the terrain. Therefore, higher Vs30 data can be obtained at higher slopes. Differences of Vs30 in the lower slope regions are less apparent because these landscapes can be equally wellsampled using the lower-resolution 30c dataset; thus, similar gradients are recovered to the higher-resolution data. Compared with the 30 arcsec SRTM DEM data, the higher resolution data assembly overestimated the Vs30 value.

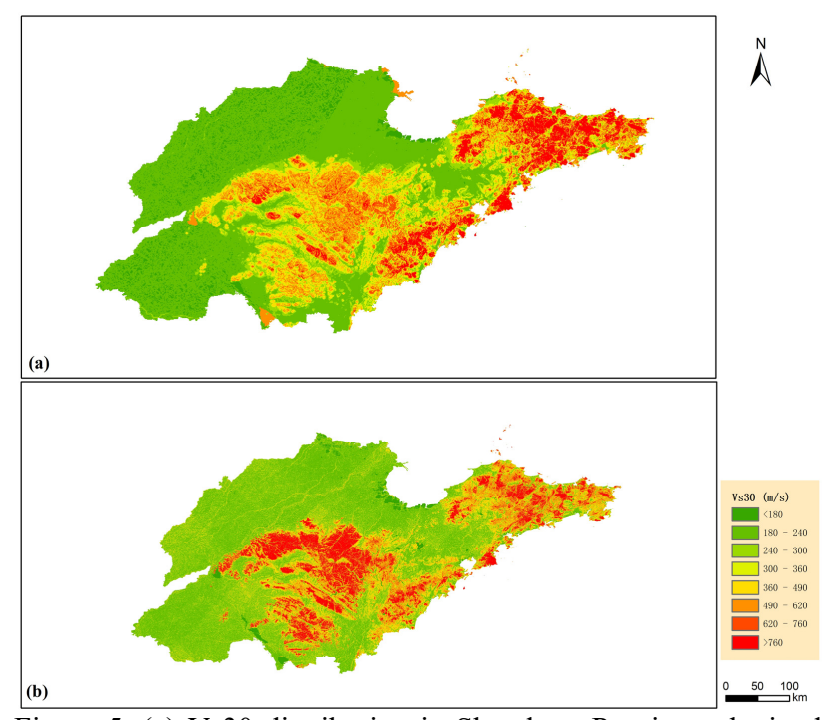

Figure 5. (a) Vs30 distribution in Shandong Province obtained from 30 arcsec DEM data. (b) Vs30 distribution in Shandong Province obtained from 3 arcsec DEM data.

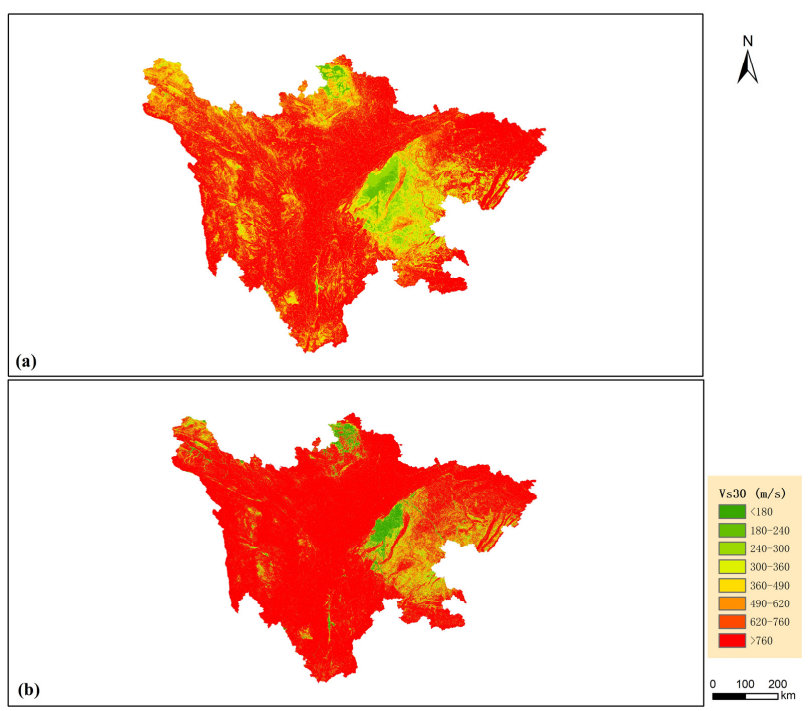

Figure 6. (a) Vs30 distribution in Sichuan Province obtained from 30 arcsec DEM data. (b) Vs30 distribution in Sichuan Province obtained from 3 arcsec DEM data.

After obtaining the Vs30 value of the study area, according to Table 1, the site classification of the study area is obtained (Figure 7 and Figure 8). In general, there is little difference in the site classification based on DEM data with different resolution. In Shandong, the main sites are stiff soil (D), very dense soil (C), soft rock $(\mathrm{C})$, and some regions are rock $(\mathrm{B})$, and a few regions are soft soil (E). In Sichuan area, rock (B) is the main site, and stiff roil (D) and soft rock $(\mathrm{C})$ are the main parts of the eastern plain. Soft soil (E) is very rare. 


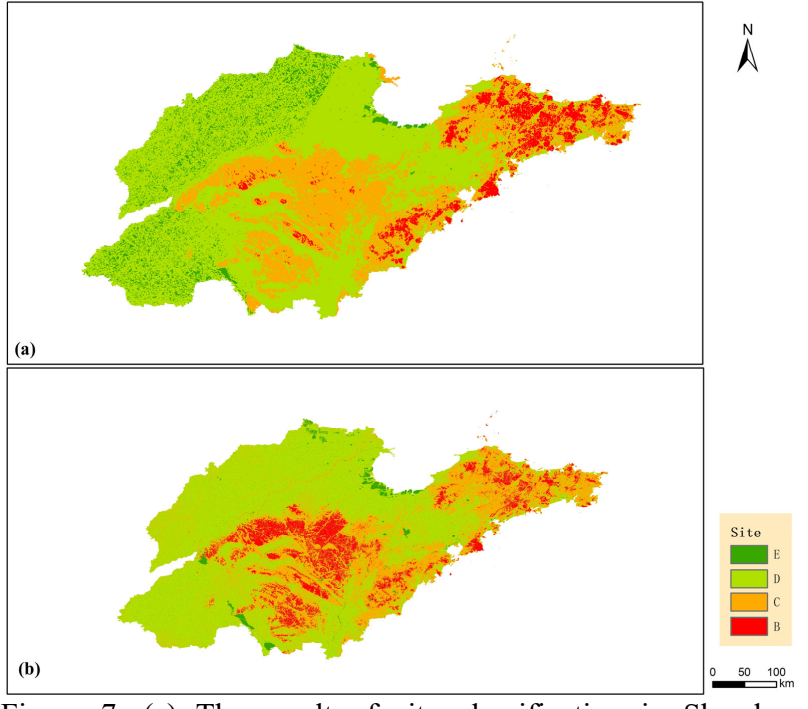

Figure 7. (a) The result of site classification in Shandong Province obtained from 30 arcsec DEM data. (b) The result of site classification in Shandong Province obtained from 3 arcsec DEM data.

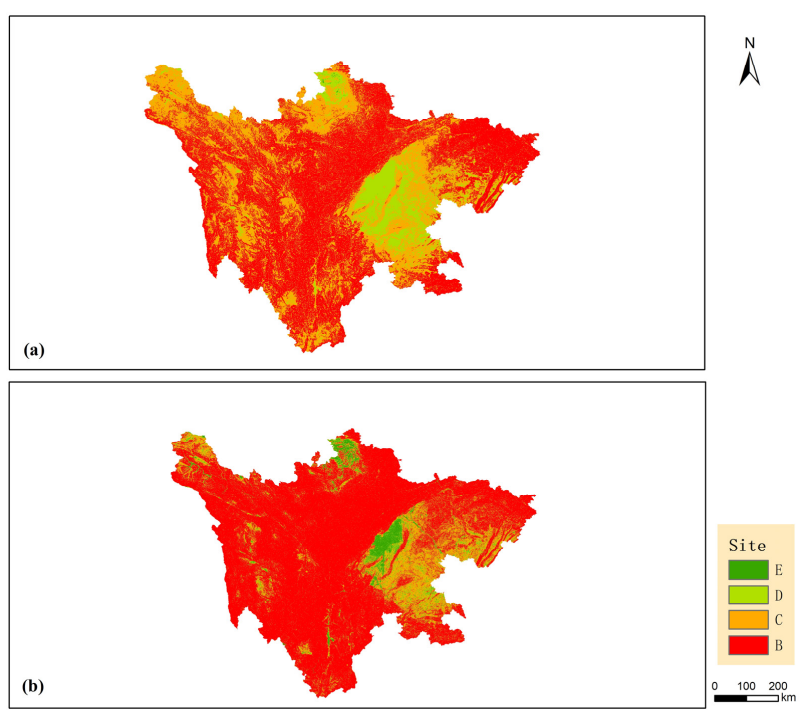

Figure 8. (a) The result of site classification in Sichuan Province obtained from 30 arcsec DEM data. (b) The result of site classification in Sichuan Province obtained from 3 arcsec DEM data.

\section{CONCLUSION}

In general, the higher resolution ( 3 arcsec) DEM data shows better at defining spatial features, but the correlation between the slope from the data and Vs30 is not better than that of when the $30 \operatorname{arcsec}$ data is used. The use of higher-resolution topography data can resolve smaller differences in gradient at higher slopes. However, it is less important to obtain accurate estimates of Vs30 in these areas because high-relief (or faster Vs30) regions are less likely to amplify ground shaking. The down sampled global SRTM 30c elevation dataset to be a reliable predictor of Vs30 (Wald and Allen, 2007) because the small-scale variations in elevation that are abundant in the high-resolution data are smoothed. The 30c maps are less sensitive to minor perturbations in gradient that are abundant in the higher-resolution SRTM data.

Using terrain data to estimate Vs30 and further determining site types, the results of Vs30 and site types are not very accurate.
However, the site information can be obtained quickly, providing reference for earthquake emergency rescue, risk assessment and engineering investigation.

In addition to the shallowest site conditions, seismic waves are also known to be strongly influenced by sediment thickness and basin structure. In the future, we will use the borehole data, geological and other data to verify and correct the Vs30 distribution and site classification results, and further study the site amplification effect.

\section{ACKNOWLEDGEMENTS}

This work was funded by National key R\&D program of China (No. 2017YFB0504104).

\section{REFERENCES}

Allen, T.I., Wald, D.J., 2009. On the use of high-resolution topographic data as a proxy for seismic site conditions (Vs30). Bulletin of the Seismological Society of America, 99(2A), pp. 935-943.

Boore, D.M., 2004a. Can site response be predicted? Journal of Earthquake Engineering, 8(1), pp. 1-41.

Boore, D.M., 2004b. Estimating Vs30 (or NEHRP Site Classes) from shallow velocity models (depths $<30 \mathrm{~m}$ ). Bulletin of the Seismological Society of America, 94(2), pp. 591-597.

Borcherdt, R.D., 1994. Estimates of site-dependent response spectra for design (methodology and justification). Earthquake Spectra, 10(4), pp. 617-653.

Chiou, B., Darragh, R., Gregor, N., and Silva, W., 2008. NGA project strong-motion database. Earthquake Spectra, 24(1), pp. 23-44.

Farr, T.G., M. Kobrick ,2000. Shuttle Radar Topography Mission produces a wealth of data. $A G U, 81$, pp. 583-585.

Lee, V.W., Trifunac, M.D., 2010. Should average shear-wave velocity in the top $30 \mathrm{~m}$ of soil be used to describe seismic amplification. Soil Dynamics and Earthquake Engineering, 30(2), pp. $1250-1258$.

Wald, D.J., Allen T.I., 2007. Topographic slope as a proxy for seismic site conditions and amplification, Bulletin of the Seismological Society of America, 97(5), pp. 1379-1395.

Wald, D.J., Quitoriano, V., Heaton, T.H., Kanamori, H., Scrivner C.W., and Worden, C.B., 1999. TriNet "ShakeMaps": Rapid generation of peak ground motion and intensity maps for earthquakes in southern California. Earthquake Spectra, 15, pp. 537-555.

Wills, C.J., Clahan, K.B., 2006. Developing a Map of Geologically Defined Site-Condition Categories for California. Bulletin of the Seismological Society of America, 96, pp. 14831501.

Wessel P., Smith W. H. F., 1991. Generic Mapping Tools. EOS, 72 , pp. 441.

Yong, A., Hough, S.E., Abrams, M.J., Cox, H.M., Wills, C.J., and Simila, G.W., 2008. Site Characterization Using Integrated 
Imaging Analysis Methods on Satellite Data of the Islamabad, Pakistan, Region. Bulletin of the Seismological Society of America, 98, pp. 2679-2693.

Yong, A., Hough, S.E., Iwahashi, J., and Braverman, A., 2012. A Terrain-Based Site-Conditions Map of California with Implications for the Contiguous United States. Bulletin of the Seismological Society of America, 102, pp. 114-128.

Zhao, J. X., Xu H., 2013. A comparison of V S30 and site period as site-effect parameters in response spectral ground-motion prediction equations. Bulletin of the Seismological Society of America, 103, pp. 1-18. 